\title{
A flame retarded chitosan binder for insulating miscanthus/recycled textile fibers reinforced biocomposites
}

\author{
Roland El Hage $\mathbb{1 D}^{1,2}$ Yasmina Khalaf, ${ }^{1,2}$ Clément Lacoste, ${ }^{3}$ Michel Nakhl, ${ }^{1,2}$ Patrick Lacroix ${ }^{4}$ \\ Anne Bergeret ${ }^{3}$ \\ ${ }^{1}$ Laboratoire de Chimie Physique des Matériaux (LCPM), Faculté des Sciences II, Université Libanaise, Fanar, Liban \\ ²Plateforme de Recherche en Nanosciences et Nanotechnologies, Université Libanaise, Fanar, Liban \\ ${ }^{3}$ Centre des Matériaux des Mines d'Alès (C2MA), IMT Mines d'Alès, Université de Montpellier, 6 Avenue de Clavières, 30319, Alès \\ Cedex, France \\ ${ }^{4}$ Greenpile, 30 rue Pierre Brasseur, 77100, Meaux, France \\ Correspondence to: R. El Hage (roland_hag@ul.edu.lb)
}

\begin{abstract}
The main objective of this study is devoted to the development of new insulating and ignifuged miscanthus fibers (Mf)/ recycled textile fibers (RTf) reinforced biocomposites (BCs) using chitosan as polysaccharide-based binder and aluminum trihydroxide (ATH) fillers while focusing on the fire behavior. To achieve this goal, a preliminary study was carried out on flame retarded chitosanbased films with various ATH-filler ratios (20,33, 50, and $60 \mathrm{wt} \%)$. ATG and pyrolysis-combustion flow calorimeter analysis showed significant improvement of chitosan thermal behavior with the addition of 33 wt \% and above of ATH. Mechanical properties of films were, however, degraded. Thereafter, different ratios of miscanthus/RTf reinforced BCs (fibers content up to 89.5-90 wt \%) were elaborated through thermocompression process using neat chitosan and chitosan/ATH (67/33 wt \%) as a binder. Mechanical, thermal, and fire behavior were evaluated. Higher mechanical properties were found for hybrid materials containing the association of both RTf and Mf in comparison to those containing only RTf or Mf. Fireproof BCs (E rating: according to the NF EN ISO 11925-2), with thermal conductivity values between 0.07 and $0.09 \mathrm{~W} \mathrm{~m}^{-1} \mathrm{~K}^{-1}$ and density range between 270 and $299 \mathrm{~kg} \mathrm{~m}^{-3}$ were successfully elaborated. The results of this study show a promising use of the chitosan/ATH system as flame retardant for biobased insulating building materials.
\end{abstract}

KEYWORDS: chitosan/ATH flame-retardant; fire-proof biocomposites; insulating materials; miscanthus; recycled textile fibers

\section{INTRODUCTION}

Global warming is one of the major problems of this century, which is the consequences of human activities associated with significant consumption of fossil fuels and materials for decades. That is why the control of energy and the substitution of fossil resources by renewable bio-sourced materials are of prime importance. In this context, a sustainable development and eco-design perspective for the building trades (new constructions and renovation) is important to find alternative solutions to traditional insulating materials ${ }^{1}$ (e.g., expanded polystyrene and polyurethane foams). Among them, using biobased, renewable, or recycled resources are deeply considered this last decade.

Among agricultural byproducts, Miscanthus $\times$ Giganteus has attracted considerable attention as dedicated lignocellulosic energy crop. Miscanthus is a noninvasive perennial grass (sterile hybrid) that requires little or no herbicide and nitrogen. Despite its high water use efficiency (2.2 $\left.\mathrm{g} \mathrm{DM} \mathrm{kg}^{-1} \mathrm{H}_{2} \mathrm{O}\right)$, calculated on the basis of harvested dry matter), ${ }^{2}$ it grows over $3 \mathrm{~m}$ tall per year and is a high productive crop which produces $15-30$ tons of dry matter per hectare compared to flax (7-9 tons $\mathrm{ha}^{-1}$ ) and hemp (6-21 tons $\left.\mathrm{ha}^{-1}\right){ }^{3,4}$ It can be cultivated in most climatic zones while other crops like hemp has been selected only for three climatic zones, and flax for six climatic zones. ${ }^{4}$ Pests and diseases were found to have no significant impact on miscanthus crop. ${ }^{5}$ For all these purposes, such kind of raw material could be considered as a potential candidate for the design of green composites. ${ }^{6-8}$

Textile wastes which are very abundant all over the world, seems to be challenging materials since that they can be converted into marketable recycled fibers. These fibers are composed from unique type or mixed natural (e.g., cotton) and synthetic fiber (e.g., polyester and acrylic). The main valorization of such product is based on incineration which could release toxic fumes in the environment. ${ }^{9}$ The other valorization is the production of lightweight insulating panel rolls/batts and loose flock for blown-in 
Table I. Composition of the Chitosan-Based Films

\begin{tabular}{llll}
\hline & $\begin{array}{l}\text { Chitosan solution } \\
(4 \% \mathrm{w} / \mathrm{v})(\mathrm{mL})\end{array}$ & ATH (g) & $\begin{array}{l}\text { Nomenclature } \\
\text { used for films }\end{array}$ \\
\hline $\begin{array}{l}\text { Neat chitosan } \\
\text { Chitosan/20 wt } \\
\% \text { ATH }\end{array}$ & 100 & 0 & FOATH \\
$\begin{array}{l}\text { Chitosan/33 wt } \\
\% \text { ATH }\end{array}$ & 100 & 1 & F20ATH \\
$\begin{array}{c}\text { Chitosan/50 wt } \\
\% \text { ATH }\end{array}$ & 100 & 2 & F33ATH \\
$\begin{array}{c}\text { Chitosan/60 wt } \\
\% \text { ATH }\end{array}$ & 100 & 4 & F50ATH \\
\hline
\end{tabular}

building applications. ${ }^{10}$ Finally, textile fiber wastes can be valorized by their incorporation into inorganic matrices (e.g., concrete blocks, ${ }^{11}$ mud-brick structures, ${ }^{12}$ hydraulic lime ${ }^{13}$ and natural hydraulic lime $\mathrm{e}^{14}$ ) as well as in organic and hybrid (e.g., polymer concrete ${ }^{15}$ ) matrices. One paper proposed to combine agricultural byproducts and textile wastes using an urea formaldehyde binder. ${ }^{16}$ Nevertheless formaldehyde based resins are considered as a probable human carcinogen and a potential long-term health effects. Several efforts were made to decrease or eliminate formaldehyde by preparing formaldehyde-free adhesive formulations using a nonvolatile, less toxic aldehyde, namely, glyoxal and by developing adhesives from natural materials. ${ }^{17-19}$ However, these natural resins need to be thermally activated for several hours (up to $8 \mathrm{~h}$ ) and their reticulation is achieved at high temperatures (up to $200{ }^{\circ} \mathrm{C}$ ).

A lightweight insulating composite having competitive thermal conductivity $\left(0.056-0.058 \mathrm{~W} \mathrm{~m}^{-1} \mathrm{~K}^{-1}\right)$ and mechanical properties (maximum stress of $2 \mathrm{MPa}$ ) was successfully developed at low temperature $\left(50{ }^{\circ} \mathrm{C}\right)$ using sunflower's stalks particles and chitosan as a binding agent. ${ }^{20}$ This study demonstrated the advantage of using a chitosan-based binder for the development of a high-performance material composed of particles size grading up to $3 \mathrm{~mm}$.

However, another very important property is requested for building materials which is based on the development of fire resistant materials to avoid fire risk. Natural fibers and biopolymers are susceptible to ignition and combustion. ${ }^{21}$ That is why the flammability property of biocomposites (BCs) which depends on the matrix polymer, the type of fibers, and the interactions between them should be investigated and improved. Enhancing flame retardancy could be realized by fibers flame retardants (FRs) grafting modification ${ }^{22}$ or directly incorporated in the matrix during materials shaping. Due to environmental concerns related to toxic gases releasing during burning, researchers have focalized on replacing halogen-containing FRs in natural fiber reinforced composites by positive environmental impact FRs such as phosphorus-based, ${ }^{23}$ halogen-free,${ }^{24}$ mineral fillers, ${ }^{25}$ and biopolymers. ${ }^{26}$ The most important criterion to evaluate the flammability properties is related to the char formation ability during burning which play an important role as heat barrier by inhibiting the flame propagation. ${ }^{27}$

Recently, green chitosan-based systems combining sodium polyphosphate, ${ }^{28}$ lignosulfonate, ${ }^{29}$ ammonium polyphosphate, ${ }^{30}$ urea $^{31}$ have been investigated for intumescence and charing flame retardancy improving. However, the presence of aluminum-based fillers such as pseudoboehmite ${ }^{32}$ in the presence of chitosan has been only investigated in the perspective to develop nanocomposite films for specific food packaging applications.

Therefore, the present work is devoted to the development of new insulating and ignifuged BCs based on the two studies discussed above, ${ }^{16,20}$ while focusing on the fire behavior. To achieve this goal, physical, mechanical, and thermal characterizations were firstly achieved on neat chitosan and on ignifuged chitosan films. Thereafter, different BCs were prepared using miscanthus and recycled textile fibers (RTf) binded by neat chitosan and

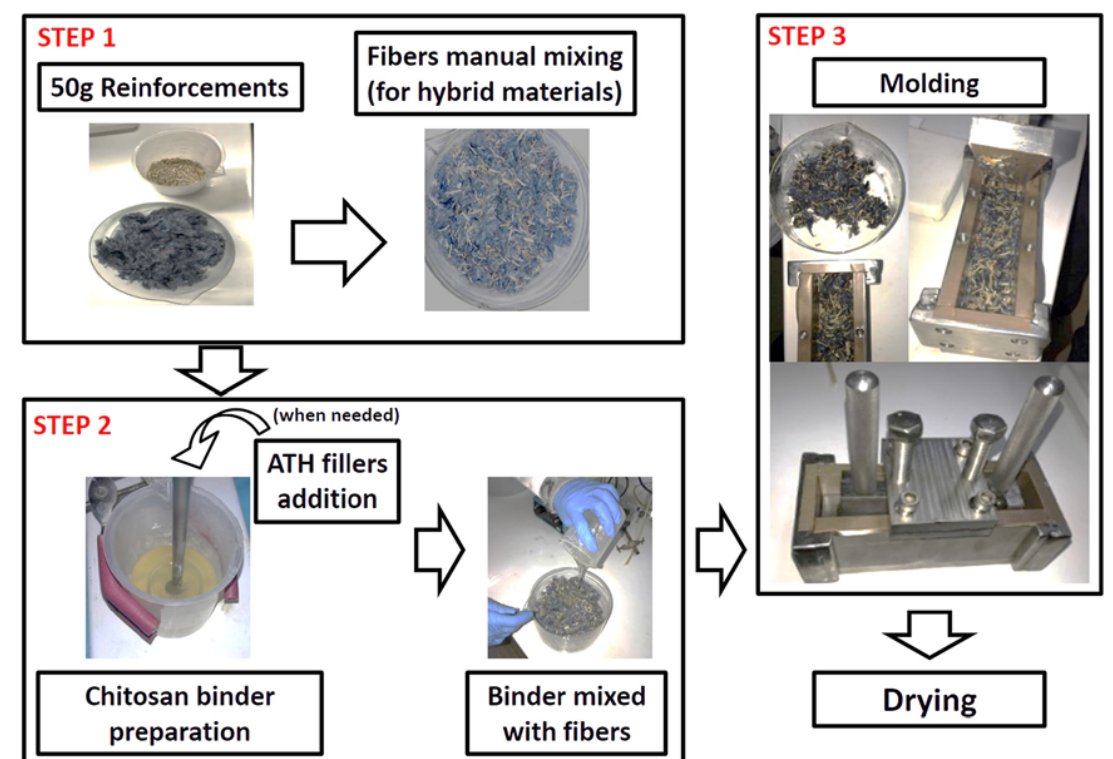

Figure 1. Schematic representation of the BCs manufacturing process. [Color figure can be viewed at wileyonlinelibrary.com] 
Table II. Data of the Different Formulations of the Prepared Biocomposites

\begin{tabular}{|c|c|c|c|c|c|c|c|}
\hline $\begin{array}{l}\text { Miscanthus /textile } \\
\text { fibers (wt \%) }\end{array}$ & Miscanthus (g) & $\begin{array}{l}\text { Textile } \\
\text { fibers }(g)\end{array}$ & $\begin{array}{l}\text { Chitosan solution } \\
(4 \% \mathrm{~m} / \mathrm{v})(\mathrm{mL})\end{array}$ & ATH (g) & $\begin{array}{l}\text { Fibers/matrix/ } \\
\text { fillers (\%) }\end{array}$ & $\begin{array}{l}\text { Nomenclature used } \\
\text { for biocomposites }\end{array}$ & Density $\left(\mathrm{kg} \mathrm{m}^{-3}\right)$ \\
\hline $100 / 0$ & 50 & 0 & 100 & 0 & $92 / 8 / 0$ & BC100/0-0 & $247 \pm 8$ \\
\hline $100 / 0$ & 50 & 0 & 100 & 2 & $89.5 / 7 / 3.5$ & BC100/0-ATH & $269 \pm 1$ \\
\hline $80 / 20$ & 40 & 10 & 100 & 0 & $92 / 8 / 0$ & BC80/20-0 & $299 \pm 2$ \\
\hline $80 / 20$ & 40 & 10 & 100 & 2 & $89.5 / 7 / 3.5$ & BC80/20-ATH & $286 \pm 1$ \\
\hline $50 / 50$ & 25 & 25 & 100 & 0 & $92 / 8 / 0$ & BC50/50-0 & $270 \pm 7$ \\
\hline $50 / 50$ & 25 & 25 & 100 & 2 & $89.5 / 7 / 3.5$ & BC50/50-ATH & $284 \pm 9$ \\
\hline $0 / 100$ & 0 & 50 & 100 & 0 & $92 / 8 / 0$ & BCO/100-0 & $286 \pm 7$ \\
\hline
\end{tabular}

ignifuged chitosan. Physical, thermal, mechanical, and fire behavior were investigated for the different formulations.

\section{EXPERIMENTAL}

\section{Materials}

Miscanthus $\times$ Giganteus was harvested in summer 2015 in French Brittany (Cap Sizun) and trade marked by EARL Ar Gorzenn (Pont Croix, France). Dried miscanthus was milled to particle size of 2-6 cm using a Wiley mill, stored at room temperature.

RTf, trademark METISSE, having an average $6 \pm 3 \mathrm{~mm} / 15 \pm 3$ $\mu \mathrm{m}$ (length/diameter) were provided by Le Relais Co. (Bruay La Buissière, France). These RTf derived from recycled second-hand jeans previously collected were used as they were received.

White to light-tan commercial powder grade chitosan with an average molecular weight of $250000 \mathrm{~g} \mathrm{~mol}^{-1}$, a deacetylation degree above $90 \%$ and a viscosity of $30-100$ cps was purchased from Glentham Life Sciences (Corsham-Wiltshire, UK). Glacial acetic acid (purity $\geq 99.7 \%$ ) used for chitosan dissolution, was purchased from VWR International (France) and used as received.

Commercial platelet aluminum trihydroxide (ATH) with mean particle size D50 of $15 \mu \mathrm{m}$ was supplied by Merck KGaA group (Darmstadt, Germany) and used as a FR.

\section{Chitosan and Chitosan/ATH Films Preparation}

A neat chitosan aqueous solution was prepared at room temperature $\left(22{ }^{\circ} \mathrm{C}\right)$ by dissolving $4 \mathrm{~g}$ of chitosan flakes into $100 \mathrm{~mL}$ glacial acetic acid solution $2 \%(\mathrm{w} / \mathrm{v})$. The mixture was mechanically stirred for $60 \mathrm{~min}$ while applying a rotational speed of the blade of $335 \mathrm{rpm}$. FR chitosan aqueous solutions were prepared using the same previously described protocol for chitosan dissolution. Various amounts of ATH fillers are then added to the $4 \%(\mathrm{w} / \mathrm{v})$ chitosan solution. Suspensions are stirred under mechanical mixing for $30 \mathrm{~min}$ at the same rotational speed to promote good dispersion of the fillers in the matrix and to obtain homogeneous dispersions.

Solvent evaporation technique is used for the chitosan and chitosan/ATH films elaboration. Each prepared suspension is poured into a Pyrex crystallizing dish covered with 0.03 -in. self-adhesive backing Teflon sheet and dried completely in an oven at $55{ }^{\circ} \mathrm{C}$ for $36 \mathrm{~h}$. Typically, 100-150 $\mu \mathrm{m}$ range thick films, measured using a micrometer caliper, are produced. Films are stored in sealed plastic bags inside cardboard boxes away from light and relative humidity variation before each analysis to avoid any aging phenomenon. The composition of the various prepared films (F) with ATH contents varying from 0 to $60 \mathrm{wt} \%$ is presented in Table I.

\section{BC Manufacturing}

A three-step process was investigated as shown in Figure 1. First, $50 \mathrm{~g}$ of reinforcements (miscanthus, mixture of miscanthus and textile fibers and textile fibers) are weighed. For the combined reinforcing materials, miscanthus particles, and textile fibers, a manually mixing is allowed for $10 \mathrm{~min}$ to produce a proper dispersion between the two raw materials. The second step consists in pouring $100 \mathrm{~mL}$ of chitosan-based solutions onto the fibers followed by manual mixing. Mixtures were then allowed to stand for $30 \mathrm{~min}$ to promote the reinforcements wetting. The third step is the $\mathrm{BC}$ molding manufacturing where a $200 \times 50 \times 70 \mathrm{~mm}^{3}$ metallic mold coated with a 0.03 -in. self-adhesive backing Teflon sheet is used. The mold is filled with the prepared mixtures followed by a room temperature compacting step during $10 \mathrm{~min}$ using a backing mold and a manual press until a thickness of $2 \mathrm{~cm}$ is reached. Metallic clamps are used to maintain the desired thickness after removing the press pressure. The mold containing the compacted mixture is then placed in an oven at $55^{\circ} \mathrm{C}$ for $24 \mathrm{~h}$. After that, drying for $19 \mathrm{~h}$ is performed after removal of

Table III. Experimental Parameters for Determining the Thermal Conductivity, Effusivity, and Diffusivity

\begin{tabular}{llllll}
\hline Analysis & Time interval (s) & Duration $(\mathrm{s})$ & Power $(\mathrm{W})$ & Sensor resistance $(\mathrm{W})$ & Heating time $(\mathrm{s})$ \\
\hline Thermal conductivity & 1 & 120 & 0.6 & 10.7 & None \\
Effusivity & 1 & 100 & 1.5 & 31.5 & 40 \\
Diffusivity & 1 & 180 & 0.49 & 6.2 & 40 \\
\hline
\end{tabular}




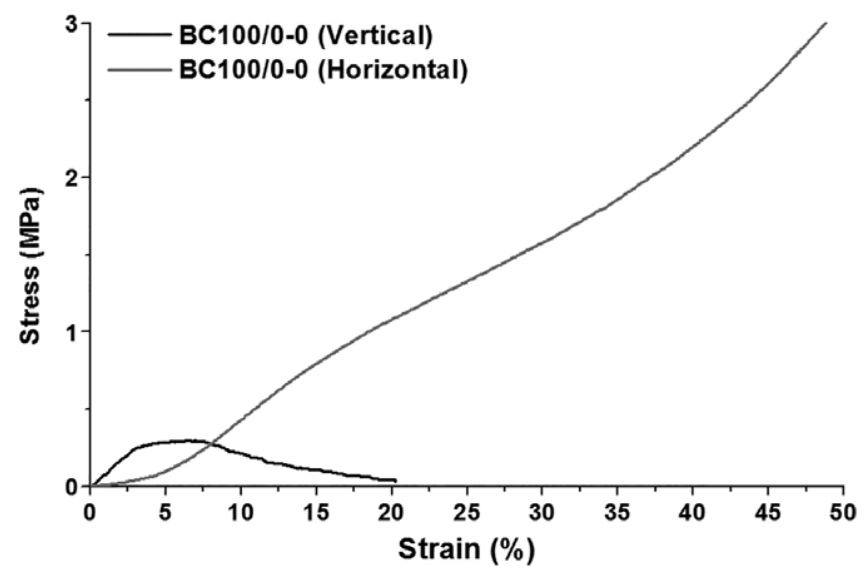

Figure 2. Stress versus strain plot for $100 \%$ miscanthus BCs (BC100/0-0) in horizontal and vertical compression.

the mold left and right edges to accelerate the BC drying. Then, $\mathrm{BCs}$ are unmolded and left in the oven for $12 \mathrm{~h}$ to perform a complete drying. Finally, samples were left in a climate room for 3 days at constant relative humidity (50\%) and temperature $\left(20^{\circ} \mathrm{C}\right)$ to verify their mass stabilization before testing.

Composition details of the various BC prepared in this study are summarized in Table II. Different ratios between miscanthus and textile fibers were studied: 100/0, 80/20, 50/50, and 0/100. A constant amount of chitosan binder and ATH were used. The average BCs apparent density (weight to volume ratio) was calculated on the basis of three samples dimensions and weights for each formulation using a caliper and an analytical balance. Results are also presented in Table II. Sample densities are in the range of 247-299 $\mathrm{kg} \mathrm{m}^{-3}$ according to the considered BC.

\section{Chitosan Films Characterizations}

Environmental Scanning Electron Microscopy Observations. Filler dispersion in the chitosan matrix is observed using a Hitachi S-4300 environmental scanning electron microscope (ESEM). Samples are deposited on the surface of a metallic support on which a double-sided bonding tape has been previously placed.

Thermal Analysis. Thermal stability of ATH fillers, chitosan, and chitosan/ATH films was investigated using a PerkinElmer Pyris-1 thermogravimetric analysis (TGA) system to measure the mass variation during the sample decomposition. Tests are carried out in alumina crucibles containing $9-10 \mathrm{mg}$ of products to be analyzed. Samples were heated under nitrogen atmosphere $(20 \mathrm{~mL}$ $\mathrm{min}^{-1}$ ) at a heating rate of $10{ }^{\circ} \mathrm{C} \mathrm{min}^{-1}$ from 20 to $800{ }^{\circ} \mathrm{C}$. Thereafter, the sample temperature was maintained isothermally for $20 \mathrm{~min}$ at $800^{\circ} \mathrm{C}$ under oxidative conditions (air) after the decreasing step. Analyses were carried out twice in order to verify the reproducibility of the results. An uncertainty of $2 \%$ was obtained for maximum peak temperature $\left(T_{\max }{ }^{\circ} \mathrm{C}\right)$ and residues at $800{ }^{\circ} \mathrm{C}(\%)$.

Differential scanning calorimetry (DSC) analyses were performed on samples containing 2-3 mg of chitosan-based films for observation of heat effects. All measurements were carried out with a scan ranging from 50 to $250{ }^{\circ} \mathrm{C}$ with a PerkinElmer Diamond calorimeter under continuous flow of dry nitrogen gas $(50 \mathrm{~mL}$ $\min ^{-1}$ ) at a heating and cooling rate of $10{ }^{\circ} \mathrm{C} \min ^{-1}$. Each analysis was repeated two times.

Fire Properties. FR properties [heat release rates (HRRs) as a function of temperature] of the various films were studied using a pyrolysis combustion flow calorimeter (PCFC, FTT Company). Total of $2-3 \mathrm{mg}$ of each formulation were pyrolyzed by heating up to $750{ }^{\circ} \mathrm{C}$ at a heating rate of $1{ }^{\circ} \mathrm{C} \mathrm{s}^{-1}$ under a nitrogen flow. Gases released from samples pyrolysis are sent into a combustor and fully oxidized in the presence of oxygen (20\%) at a temperature of $900{ }^{\circ} \mathrm{C}$. Each sample was analyzed at least three times. Average values (from three measurements) of $\mathrm{pHRR}, \mathrm{T}_{\max }{ }^{\circ} \mathrm{C}$ (temperature at $\mathrm{pHRR}$ ) and THR, were determined by processing the obtained curves with the PCFC EZ software.

Mechanical Properties. Uniaxial tensile tests were carried out on the various prepared chitosan-based films. Maximum tensile strength $\left(\sigma_{\max }\right)$, elongation at break $\left(\varepsilon_{\mathrm{b}}\right)$, and Young's modulus $\left(E_{\mathrm{T}}\right)$ were determined according to standard ISO527-3 using a Zwick/Roell TH 010 machine equipped with a force sensor of $500 \mathrm{~N}$ on $80 \times 10 \times 0.125 \mathrm{~mm}^{3}$ rectangular dried specimens. The used thickness values $(125 \mu \mathrm{m})$ were an average of four measurements taken randomly on each specimen. Temperature and relative humidity were $20{ }^{\circ} \mathrm{C}$ and $55 \%$, respectively, and the crosshead speed was set at $1 \mathrm{~mm} \mathrm{m^{-1 }}$. A least three measurements were performed for each type of film and average values were reported.

\section{BCs Characterizations}

Microstructural Characterization. Surface observations (the presence of voids and fibers dispersion) of BCs were evaluated using a Wild Heerbrugg optical microscopy ( $\times 6$ magnifications on $2 \times 2 \mathrm{~cm}^{2}$ specimens). The porosity of the single fibers and the BCs was estimated using an AccuPyc-1340 Helium Pycnometer.

Insulating Properties. Thermal conductivity, diffusivity, and effusivity values of the various BCs were obtained using a FP2C-NeoTIM device linked to a computer for monitoring and signal processing. Three different probes inserted between two pieces of each formulation are used to obtain the different values. A weight of $3 \mathrm{~kg}$ is added to the upper surface to ensure the maintenance of the probe between the two pieces. Tests were conducted four times for each formulation on samples having $200 \times 50 \times 20 \mathrm{~mm}^{3}$ dimensions at room temperature of $20{ }^{\circ} \mathrm{C}$ and relative humidity of $50 \%$. Each formulation was conditioned in this atmosphere for $48 \mathrm{~h}$ before analysis. Experimental parameters for determining the thermal conductivity, diffusivity, and effusivity are collected in Table III. Thermal conductivity of single miscanthus and RTf (fibers bulk) were also measured at a same density $\left(132 \mathrm{~kg} \mathrm{~m}^{-3}\right)$.

Mechanical Properties. Three points bending flexural test was performed on specimens (three samples for each formulation) with dimensions $200 \times 50 \times 20 \mathrm{~mm}^{3}$ using a Zwick/Roell $\mathrm{TH}$ 010 machine equipped with a $2.5 \mathrm{kN}$ capacity load cell by setting a crosshead speed of $2 \mathrm{~mm} \mathrm{m^{-1 }}$. Compressive tests were carried out by the same equipment with a $10 \mathrm{kN}$ load cell and by setting a crosshead speed of $10 \mathrm{~mm} \mathrm{~min}^{-1}$. Compression 

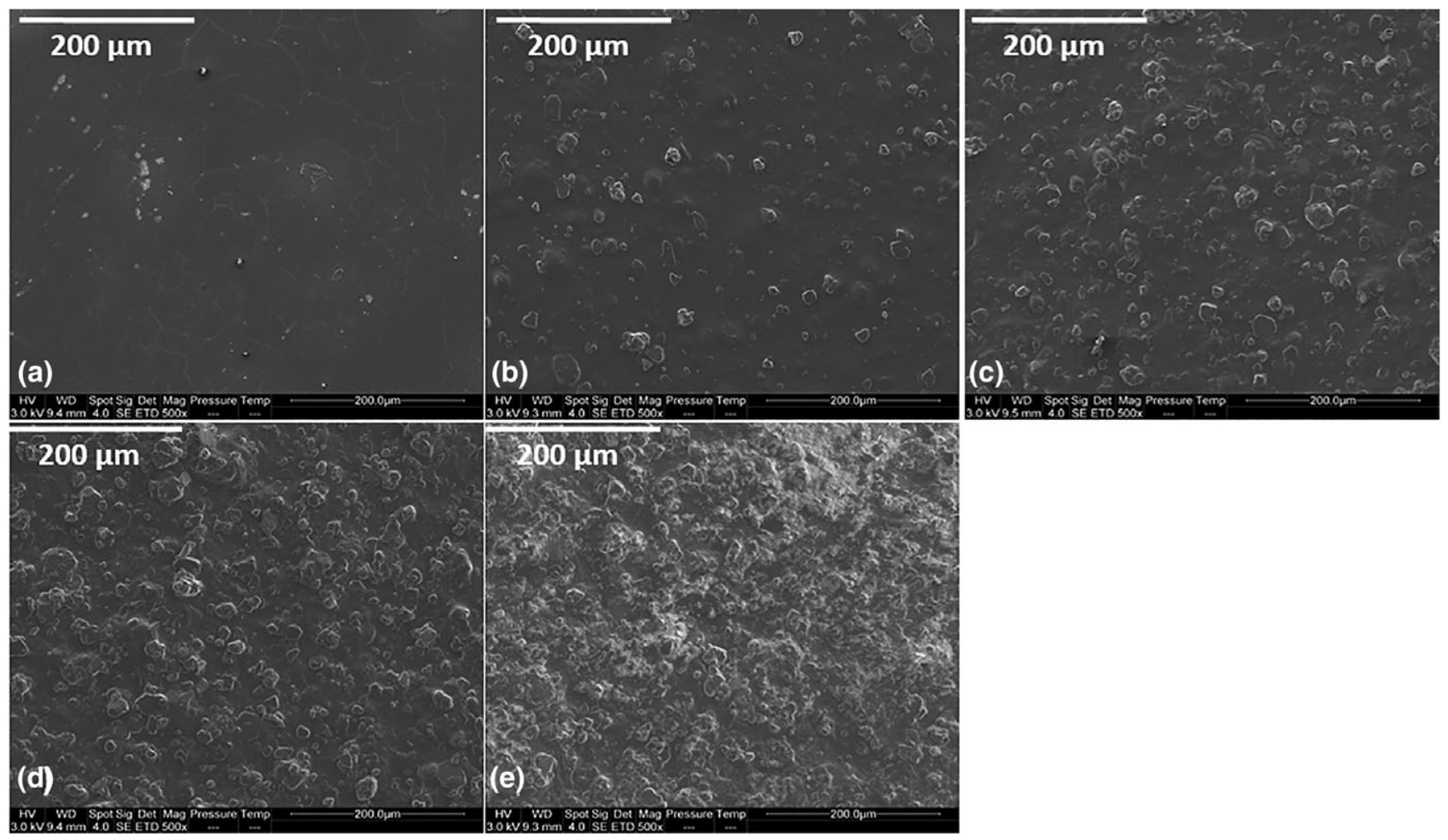

Figure 3. Surface ESEM micrographs: (a) F0ATH, (b) F20ATH, (c) F33ATH, (d) F50ATH, and (e) F60ATH.

tests were achieved in horizontal (compaction direction) and vertical direction (contrary to compaction direction) of each formulation using a prism tool of section $40 \times 40 \mathrm{~mm}^{2}$. A sample stressstrain plot in vertical and horizontal compression for $100 \%$ miscanthus $\mathrm{BC}$ is shown in Figure 2. Elastic modulus $\left(E_{\mathrm{ch}}\right)$, stress at $5 \%$ elongation $\left(\sigma_{\mathrm{ch} \chi 5 \%}\right)$, stress at $10 \%$ elongation $\left(\sigma_{\mathrm{ch} \chi 10 \%}\right)$, and stress at $20 \%$ elongation " $\sigma_{\mathrm{ch} \chi 20 \%}$ » were evaluated in the horizontal compressive mode because no failure occurs during compression. Elastic modulus $\left(E_{\mathrm{cv}}\right)$, maximum stress $\left(\sigma_{\mathrm{cv}}\right)$, and elongation at maximum stress $\left(\varepsilon_{\mathrm{cv}}\right)$ were evaluated in the vertical compressive mode because failure occurred in this position.
Fire Properties. Then, $200 \times 50 \times 20 \mathrm{~mm}^{3}$ BCs are directly exposed to a flame according to standard to NF EN ISO 11925-2 using a lab-made simulated single flame source fire as described by Hamdani-Devarennes et al. ${ }^{1}$ Propane was used as combustion gas and the air flow rate in the combustion chamber was about $0.6-0.8 \mathrm{~m} \mathrm{~s}^{-1}$. For each formulation, a set of three specimens was tested using a flame angle of $45^{\circ}$ with the vertical which was applied for a total duration of $30 \mathrm{~min}$ from the time at which the flame touched the specimens. During the test, the following information are recorded: ignition time $\left(T_{\text {igns }}\right)$; flame spread height $\left(F_{\mathrm{s}}\right)$ (qualified as the height in $\mathrm{mm}$ of the flame above the (a)

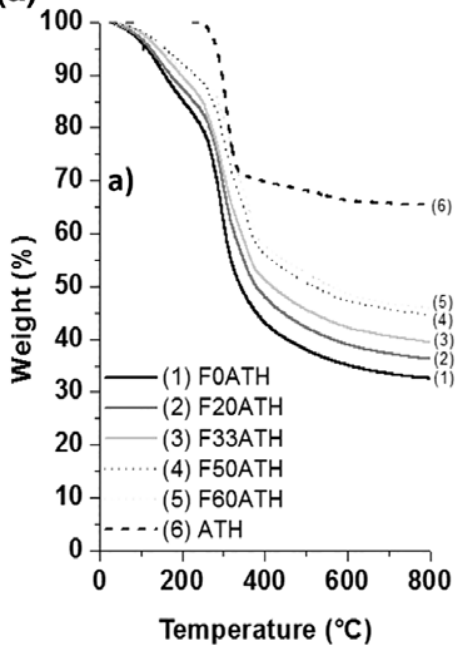

(b) 0

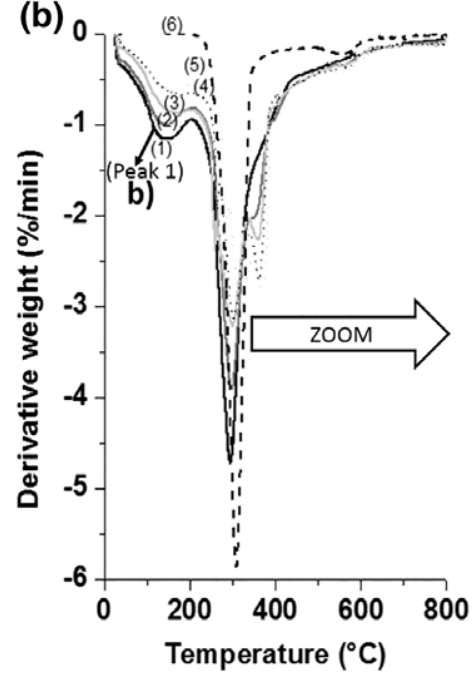

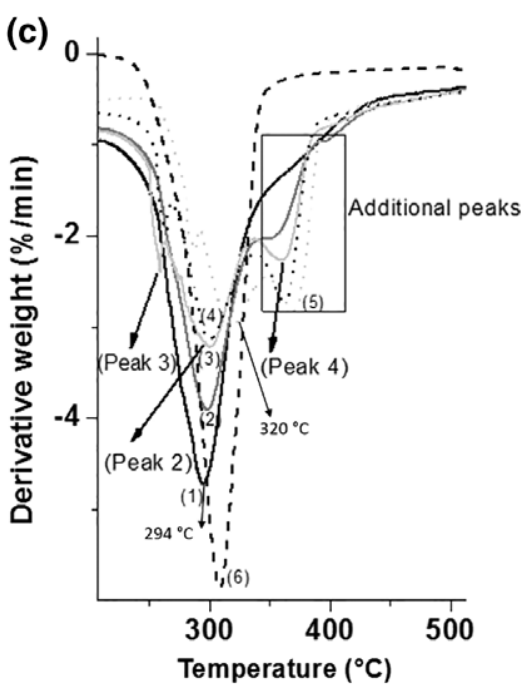

Figure 4. (a) TGA and (b) DTG curves of (1) F0ATH; (2) F20ATH; (3) F33ATH; (4) F50 ATH; (5) F60ATH; and (6) ATH. 
Table IV. TGA and DTG Results for ATH and Chitosan/ATH Films.

\begin{tabular}{lllll}
\hline Samples & $T_{\max }\left({ }^{\circ} \mathrm{C}\right)$ & $\begin{array}{l}\text { Residue }(\%) \\
\left(800{ }^{\circ} \mathrm{C}\right)\end{array}$ & $\begin{array}{l}\text { Calculated } \\
\text { residue }(\%)\end{array}$ & $\begin{array}{l}\text { Char } \\
\text { yield }(\%)\end{array}$ \\
\hline FOATH & 294 & 33 & 0 & 33 \\
F20ATH & 298 & 36 & 13 & 23 \\
F33ATH & 299 & 39 & 21 & 18 \\
F50ATH & 303 & 45 & 33 & 12 \\
F60ATH & 320 & 46 & 39 & 7 \\
ATH & 307 & 35 & 35 & 0 \\
\hline
\end{tabular}

flame application point); time at which the flame spread height reaches $150 \mathrm{~mm}\left(T_{m}\right)$ self-extinguishing time $\left(T_{\text {selfs }}\right)$; ignition of a paper filter located under the sample due to dripping $\left(T_{\text {drip }}\right)$. Euroclass rating can be determined from these data. It consists in delivering a fire level using letters as follows: Class E occurs if $F_{\mathrm{s}}$ less than $150 \mathrm{~mm}$ after $20 \mathrm{~s}$; Class E-d2 is proposed if $F_{\mathrm{s}}$ less than $150 \mathrm{~mm}$ after $20 \mathrm{~s}$ and paper filter ignition; and Class F corresponds to the case where $F_{\mathrm{s}}$ higher than $150 \mathrm{~mm}$.

\section{RESULTS AND DISCUSSION}

\section{Chitosan and Chitosan/ATH Films Characterizations}

ESEM Observations. ESEM observations were carried out on the surface of the different chitosan and chitosan/ATH films to evaluate the fillers dispersion. Results are presented in Figure 3. Two components are observed and the edge of the ATH fillers is well defined. ATH fillers are well embedded and recovered in the chitosan matrix. No empty space is observed between the filler and the matrix which indicates a good interfacial adhesion. Then, 20 and 33 wt \% ATH fillers are well dispersed in the chitosan matrix as shown. In addition, 50 and 60 wt \% ATH fillers present aggregated particles. This tendency to aggregate gradually increases with the higher amount of the introduced fillers.

Thermogravimetric Analysis. Figure 4 shows the TGA and differential thermogravimetry (DTG, TGA derivate) curves of the

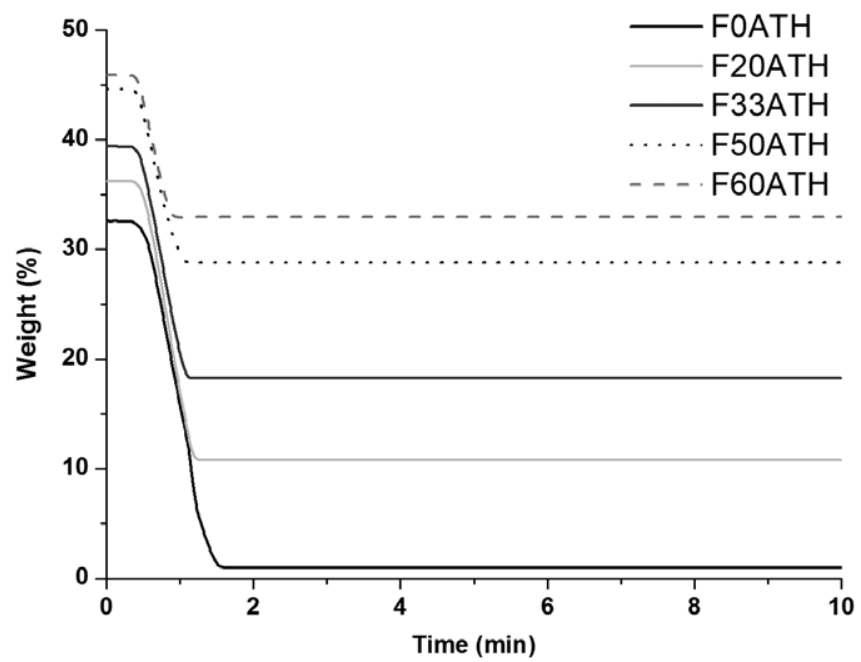

Figure 5. TGA curves of chitosan/ATH films residues at $800{ }^{\circ} \mathrm{C}$ under air atmosphere.

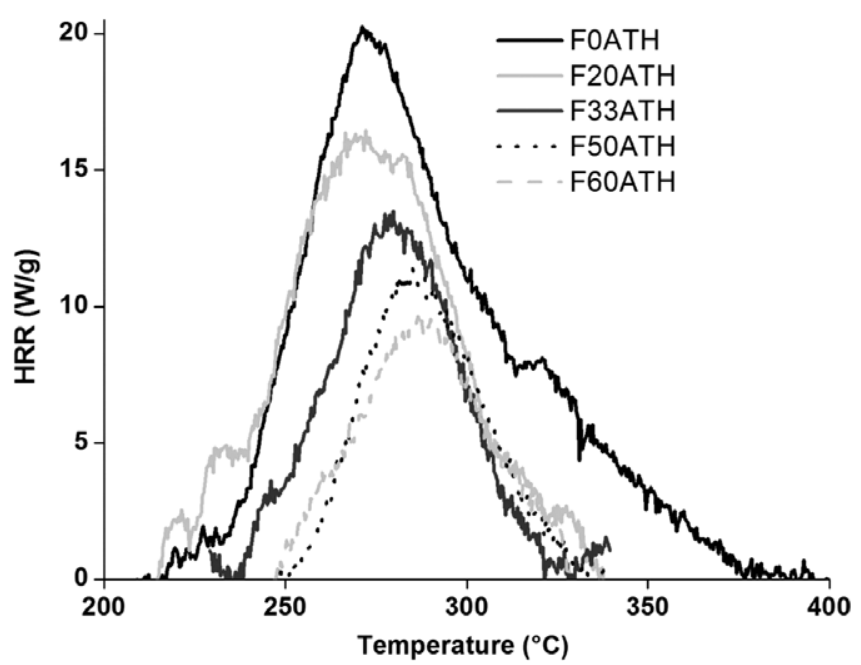

Figure 6. PCFC HRR curves of chitosan/ATH films.

raw ATH and ATH/chitosan films. Table IV summarizes the results of the maximum degradation temperature $\left(T_{\max }{ }^{\circ} \mathrm{C}\right)$, the percentage of experimental residue obtained at $800{ }^{\circ} \mathrm{C}$, and the percentage of calculated residue and the char yield (calculated as the difference between the experimental value and the calculated one). Theoretical residue for ATH is $65 \%$ and no residue is expected for chitosan as it is an organic polymer which is expected to be fully degraded.

Neat chitosan shows the fastest and greatest mass loss with a charring residue of $33 \%$. This is explained by incomplete degradation of chitosan. Derivative curve of neat chitosan shows a two-stage decomposition process. The first peak located at $142{ }^{\circ} \mathrm{C}$ (Peak 1) is attributed to the removal of moisture and volatile matter in the film ${ }^{33}$ and corresponds to a loss of $9 \%$. The second peak at $294{ }^{\circ} \mathrm{C}$ (Peak 2) corresponds to a mass loss resulting from the depolymerization and the degradation of the chitosan structure for a temperature range between 200 and $600{ }^{\circ} \mathrm{C}^{28}$ According to López et al., ${ }^{34}$ the decomposition of chitosan is a very complex reaction: various decomposition products were observed by mass spectrometry during the heat treatment. However, this degradation may be related to breakage of low-energy intramolecular and intermolecular bonds (hydrogen bonds), the decomposition of amine groups ${ }^{35}$ and the degradation of $-\mathrm{CH}_{2} \mathrm{OH}$ groups. ${ }^{36}$

As concerned ATH its dehydration occurs at $310{ }^{\circ} \mathrm{C}$ with a $35 \%$ weight loss slightly just after the beginning of the chitosan structure degradation. This can therefore impact the chitosan degradation kinetics by adding this filler.

Table V. PCFC Results for Chitosan/ATH Films

\begin{tabular}{llll}
\hline Sample & pHRR $\left(\mathrm{W} \mathrm{g}^{-1}\right)$ & $T_{\max }\left({ }^{\circ} \mathrm{C}\right)$ & THR $\left(\mathrm{KJ} \mathrm{g}^{-1}\right)$ \\
\hline FOATH & $19.40 \pm 0.92$ & $268 \pm 5$ & $1.50 \pm 0.14$ \\
F20ATH & $16.20 \pm 0.14$ & $273 \pm 5$ & $1.10 \pm 0.14$ \\
F33ATH & $13.70 \pm 0.14$ & $279 \pm 6$ & $0.70 \pm 0.00$ \\
F50ATH & $10.90 \pm 0.28$ & $281 \pm 6$ & $0.55 \pm 0.07$ \\
F60ATH & $9.40 \pm 0.14$ & $285 \pm 3$ & $0.4 \pm 0.07$ \\
\hline
\end{tabular}




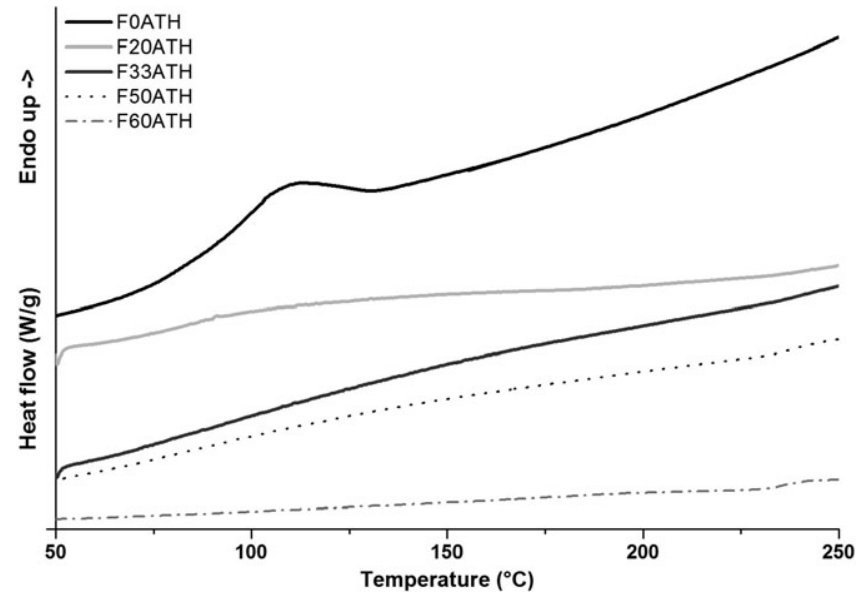

Figure 7. DSC thermograms of chitosan/ATH films.

In the presence of $\mathrm{ATH}$, a decrease in the Peak 1 height is observed due to a decrease in the hydrophilicity of the chitosan. The chitosan main chain peak was divided into three peaks after the addition of fillers. The degradation starts around $260{ }^{\circ} \mathrm{C}$ (Peak 3). A significant slower rate of chitosan thermal depolymerization is than observed after the minimum addition of $33 \mathrm{wt} \%$ of ATH resulting in a shift of the degradation temperature (Peak 2) from 294 to $320{ }^{\circ} \mathrm{C}$ after the addition of 60 wt \% of ATH and the appearance of an additional peak (Peak 4) at higher temperature. This is explained by the ATH degradation mechanism that results in structural water releases and in alumina $\left(\mathrm{Al}_{2} \mathrm{O}_{3}\right)$ formation which consequently induced the forming of a more stable structure that degrades again later by the appearance of the third peak around $360{ }^{\circ} \mathrm{C}$.

The charring rate was not promoted with the addition of ATH fillers and gradually decreases. This decrease is proportional to the amount of the added ATH, which replaces part of chitosan content in the various films. This behavior shows in fact an interesting charring behavior of chitosan itself.

TGA curves of chitosan/ATH films residues at $800{ }^{\circ} \mathrm{C}$ under air atmosphere are shown in Figure 5. Residue of neat chitosan disappears completely by loosing $33 \%$ of the remaining mass percentage. This result confirms that the degradation of chitosan under inert atmosphere produces a carbonized residue (charing effect) which oxidizes under air atmosphere and disappears.
Residue levels remain present for films containing ATH after oxidation. These residues are assigned to alumina $\left(\mathrm{Al}_{2} \mathrm{O}_{3}\right)$ formation.

PCFC Analysis. The HRR curves versus temperature of chitosan/ ATH films are shown in Figure 6. Table V summarizes the values of pHRR ( $\left.\mathrm{W} \mathrm{g}^{-1}\right)$, maximum degradation temperature $\left(T_{\max }\right)$ and THR $\left(\mathrm{kJ} \mathrm{g}^{-1}\right)$.

Pure chitosan exhibits one large HRR peak at $268 \pm 5{ }^{\circ} \mathrm{C}$ which corresponds to the depolymerization and degradation of the main structure as confirmed by the TGA analysis. Gradual increase of the maximum degradation temperature is observed with ATH content increase (from $268 \pm 5{ }^{\circ} \mathrm{C}$ for neat chitosan to $285 \pm 3{ }^{\circ} \mathrm{C}$ after adding $60 \mathrm{wt} \%$ of ATH) which indicate a slowdown of the combustion rate.

Neat chitosan has a pHRR value of $19.40 \pm 0.92 \mathrm{~W} \mathrm{~g}^{-1}$ which is very low in comparison with other traditional polymers as, for example, poly(methyl methacrylate), ethylene vinyl acetate, epoxies, poly(lactic acids), and flexible polyurethane foams with pHRR values of $400,{ }^{37} 633,{ }^{38} 378.5,{ }^{39} 426,{ }^{40}$ and $400 \mathrm{~W} /$ $\mathrm{g}{ }^{41}$ respectively. Overall, a decreasing of $\mathrm{pHHR}$ values is observed with the gradual increase of the mineral filler content from $19.40 \pm 0.92 \mathrm{~W} \mathrm{~g}^{-1}$ for F0ATH to $9.40 \pm 0.14 \mathrm{~W} \mathrm{~g}^{-1}$ for F60ATH due to dilution effect. However, THR values exhibit a decrease of about $27,53,63$, and $73 \%$ after adding $20,33,50$, and 60 wt $\%$ of ATH. This evolution does not follow the dilution rate which is explained by a deceleration of combustion induced by the endothermic character of ATH which cooled the system and diluted the flammable gases and free radicals by structural water releasing. ${ }^{38}$ These results clearly show that the use of chitosan alone as a matrix is very advantageous in the design of a material with improved fire behavior and that the addition of a minimum content of $33 \mathrm{wt}$ $\%$ of ATH may cause significant deceleration of the combustion as observed by the significant drop in THR values which consequently reduces the fire dangerousness.

\section{DSC RESULTS}

Figure 7 presents the DSC thermograms of pure chitosan and chitosan/ATH samples. Neat chitosan presents a large endothermic peak at around $100{ }^{\circ} \mathrm{C}$. This peak is attributed to moisture
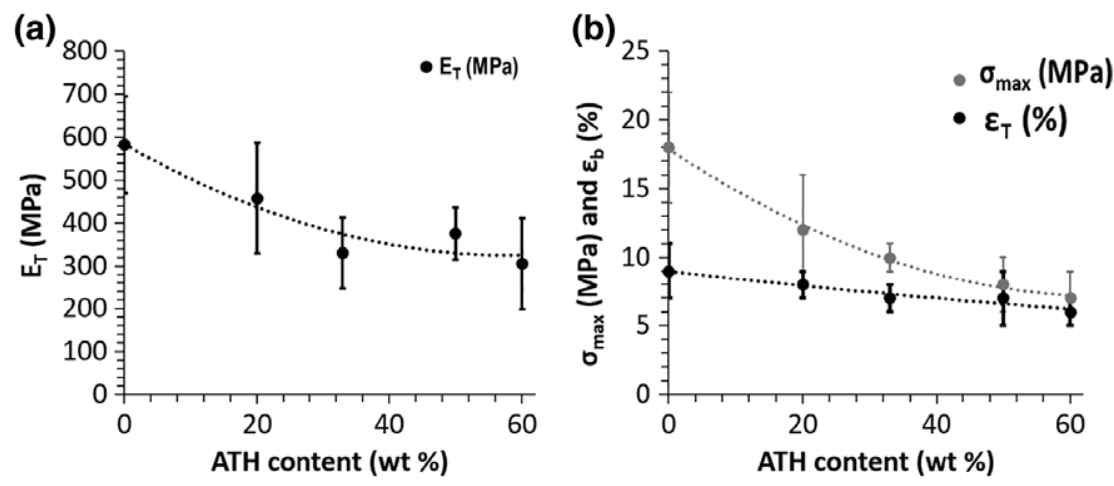

Figure 8. Tensile properties of chitosan/ATH films (a) Young's modulus $E_{\mathrm{T}}$ and (b) maximum tensile strength $\sigma_{\max }$ and elongation at maximum strength $\varepsilon_{\mathrm{T}}$ (dotted lines correspond to a nonlinear regression). 


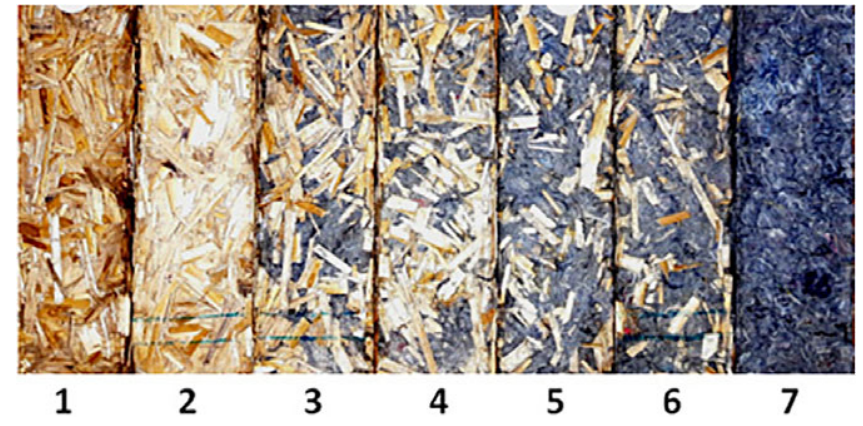

Figure 9. Pictures of the developed BCs; 1: BC100/0-0, 2: BC100/0-ATH, 3: BC80/20-0, 4: BC80/20-ATH, 5: BC50/50-0, 6: BC50/50-ATH, and 7: $\mathrm{BC} 0 / 100-0$. [Color figure can be viewed at wileyonlinelibrary.com]

loss which is associated with bounded water molecules to the polar groups (hydroxyl and amine) present in the structure of the chitosan. ${ }^{42}$ This endothermic peak becomes less intense and more spread out and then disappears with the introduction of a maximum quantity of $60 \mathrm{wt} \%$ of ATH. These observations are in agreement with the results obtained by TGA which showed increasing of the chitosan hydrophobicity with the gradual addition of the ATH. DSC curves do not show any phase transition peak such as glass transition. This behavior agrees with other author's studies. $^{33,43,44}$

\section{Tensile Properties}

Figure 8 shows the results of the tensile test performed on chitosan/ATH films. The mean elasticity modulus $\left(E_{\mathrm{T}}\right)$, maximum tensile strength $\left(\sigma_{\max }\right)$, elongation at maximum strength values $\left(\varepsilon_{\mathrm{T}}\right)$ of neat chitosan are $582 \pm 112 \mathrm{MPa}, 18 \pm 4 \mathrm{MPa}$, and $9 \pm 2 \%$, respectively. Literature ${ }^{32,45,46}$ evoked widely ranging values for Young's modulus (2-9 GPa) and tensile strength (5-160 MPa) for neat chitosan films. These variations are related to the degree of deacetylation, the molecular weight, the origin of powdered chitosan, and to other parameters such as the experimental method preparation (chitosan concentration and drying temperature), the storage conditions, and experimental working conditions (film thicknesses, relative humidity, and temperature).
$E_{\mathrm{T}}$ and $\sigma_{\max }$ decreased with the progressive addition of ATH and reached a value of $305 \pm 107 \mathrm{MPa}(51 \%$ drop) and $7 \pm 2 \mathrm{MPa}$ (61\% drop), respectively, after incorporation of 60 wt \% of ATH. Thus, chitosan partially loses its elasticity by introducing this aluminum filler as shown by the maximum elongation mean values which decreased from 9 to $6 \%$ for the maximum loaded film. This behavior could be related to the destruction of hydrogen bonding between chitosan chains ${ }^{46}$ and to fillers aggregation as confirmed by the MEB observations results. Both phenomena could be in competition as shown by Shittu et al. ${ }^{32}$ that observed no evolution of tensile properties with increased pseudoboehmite alumina filler contents in chitosan films from 1 to $5 \mathrm{wt} \%$. The high agglomeration potential of nanofillers may counterbalance the destruction of $\mathrm{H}$ bonds between chitosan chains.

\section{BCs Characterizations}

Microstructural Characterization. Pictures of the BCs are presented in Figure 9 and observations by optical microscope in Figure 10. As shown in these figures, miscanthus and textile fibers are randomly oriented in all formulations. The presence of significant pores is clear in all the formulations except that containing only textile fibers. An increasing in the entanglement of the fibers is also observed with the progressive increase in the amount of textile fibers. The presence of porosity, which limits the propagation of heat and sound, is important in the design of a high density insulating material. A glossy layer of chitosan can be observed on the fibers surface. This indicates good coating of this binder on the fiber surfaces. Table VI presents the porosity values of the single fibers and the BCs. Results show higher porosity values for the miscanthus fibers (Mf, 87\%) in comparison to RTf (67\%). The porosity seems to be similar for the various BCs formulations (around 70-80\%). However, a slight insignificant increase is observed with the gradual addition of the RTf.

Thermal Properties. The thermal conductivity evolution of fibers and of BCs as a function of density is presented in Figure 11 and compared to some results extracted from literature. It appears that the thermal conductivity varies between $0.069 \pm 0.002$ and $0.090 \pm 0.001 \mathrm{~W} \mathrm{~m}^{-1} \mathrm{~K}^{-1}$ so that BCs of this study can be

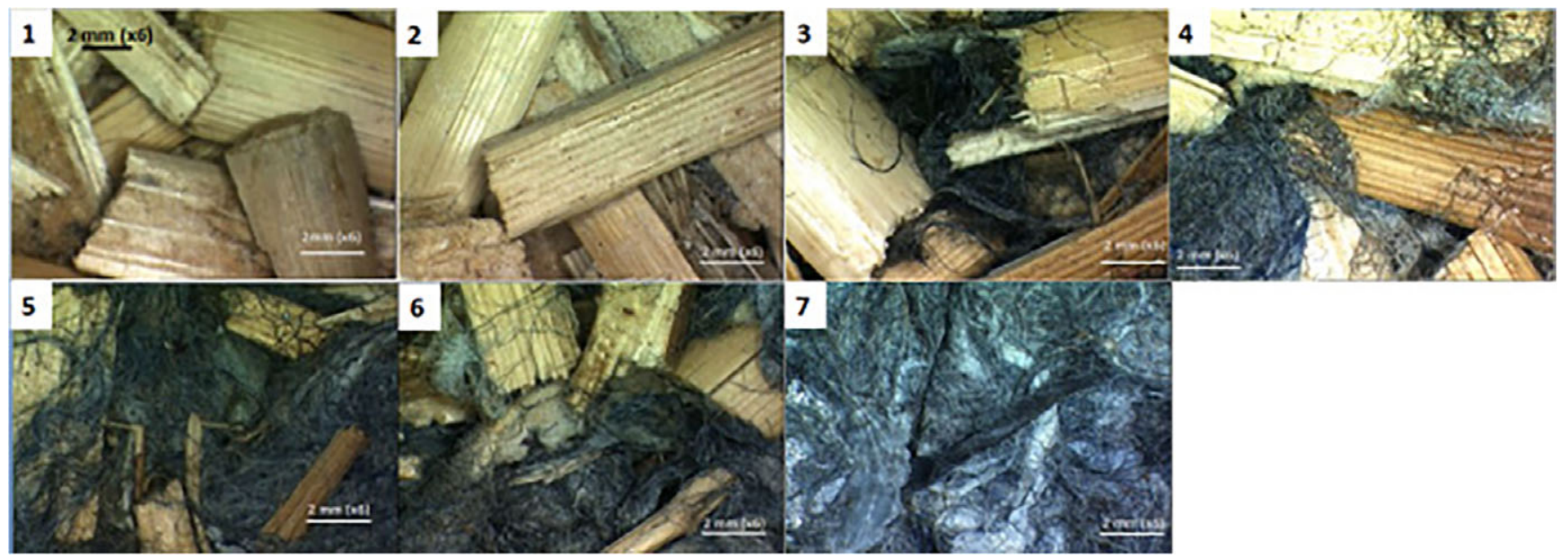

Figure 10. Microscopic observations (×6): 1: BC100/0-0, 2: BC100/0-ATH, 3: BC80/20-0, 4: BC80/20-ATH, 5: BC50/50-0, 6: BC50/50-ATH, and 7: $\mathrm{BC} 0 / 100-0$. [Color figure can be viewed at wileyonlinelibrary.com] 
Table VI. Porosity Values of Single Fibers and Biocomposites

\begin{tabular}{lllllll}
\hline Samples & Mf & RTf & BC100/0 & BC80/20 & BC50/50-0 & BC0/100-0 \\
\hline Porosity (\%) & 87 & 67 & $71 \pm 3$ & $73 \pm 4$ & $76 \pm 3$ & $78 \pm 2$ \\
\hline
\end{tabular}

considered as insulating materials. ${ }^{47}$ This variation is correlated to density variation (247-299 $\mathrm{kg} \mathrm{m}^{-3}$ ). Moreover, it seems that textile content increasing leads to higher thermal conductivity values despite that thermal conductivity value of $\mathrm{Mf}$ is slightly higher $\left(0.063 \pm 0.002 \mathrm{~W} \mathrm{~m}^{-1} \mathrm{~K}^{-1}\right)$ than that of RTf $(0.059 \pm 0.001 \mathrm{~W}$ $\left.\mathrm{m}^{-1} \mathrm{~K}^{-1}\right)$ measured at a same density $\left(132 \mathrm{~kg} \mathrm{~m}^{-3}\right)$. This is related to fibers wettability behavior and to the highest compaction caused by the presence of the textile fibers which induces a decrease in the voids presence as shown by the microscopic observations. Based on literature, it should be noted that the thermal conductivity value of pure chitosan is very high ${ }^{48}$ and was obtained to be $0.32 \mathrm{~W} \mathrm{~m}^{-1} \mathrm{~K}^{-1}$. During BCs shaping, unlike to $\mathrm{Mf}$, a remarkable wettability of textile fibers with the chitosan binder suspensions was observed. This behavior indicate not only a superficial binder coating but also a binder penetration inside the fibers core which leads to higher thermal conductivity values caused by the elimination of the internal fibers pores which was filled by the chitosanbased binder.

Comparing to literature, these thermal performances obtained in this study are better than those of sunflower free binder panels called S-F in Figure $11 \quad\left(d=500 \mathrm{~kg} \mathrm{~m}^{-3} ; \quad \lambda=0.088 \mathrm{~W}\right.$ $\left.\mathrm{m}^{-1} \mathrm{~K}^{-1}\right),{ }^{49}$ of palm fiber gypsum-based panels called pulse field gradient (PFG, $d=753 \mathrm{~kg} \mathrm{~m}^{-3} ; \lambda=0.15 \mathrm{~W} \mathrm{~m}^{-1} \mathrm{~K}^{-1}$ ) ${ }^{50}$ and of urea formaldehyde sunflower stem/stalk fibers and textile wastebased panels called SST-U $\left(d=150 \mathrm{~kg} \mathrm{~m}^{-3} ; \quad \lambda=0.1114 \mathrm{~W}\right.$ $\left.\mathrm{m}^{-1} \mathrm{~K}^{-1}\right) .{ }^{16}$ However, thermal conductivity values of this study remain greater and less efficient than insulating biobased composite made from sunflower stalks particles and chitosan (called SC15 in Figure 11$)^{20}$ which reached values between 0.056 and $0.058 \mathrm{~W} \mathrm{~m}^{-1} \mathrm{~K}^{-1}$ depending on the manufacturing conditions despite the highest content of chitosan (about $15 \mathrm{wt} \%$ ). These low values are related either to the lower density of the author

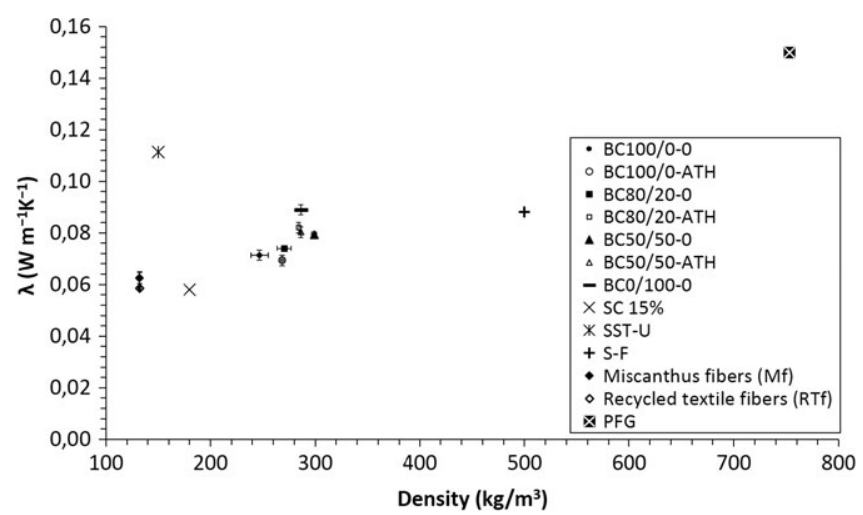

Figure 11. Figure 11 Evolution of thermal conductivity $(\lambda)$ of the BCs as a function of density in comparison with the literature (SC15\%: sunflower/ chitosan-based panels ${ }^{20}$; SST-U: sunflower stem/stalk fibers/textile wasteurea formaldehyde-based panels $^{16}$; S-F: sunflower-free binder panels ${ }^{48}$; PFG: palm fiber gypsum-based panels ${ }^{49}$ ). samples (between 150 and $200 \mathrm{~kg} \mathrm{~m}^{3}$ ) or to the natural porous structure of their sunflower particles which remained intact (no penetration into the sunflower cell walls is observed) after BCs shaping as shown by the MEB analysis.

The heat transfer velocity which corresponds to the thermal diffusivity $\alpha\left(\mathrm{m}^{2} \mathrm{~s}^{-1}\right)$ is another parameter that can evaluate the insulation capacity of materials. Thus, heat propagation of BCs can be characterized not only on the value of thermal conductivity but also by the thermal diffusivity. ${ }^{51}$ Higher values indicate that heat passes quickly through a material. Figure 12 shows, respectively, the evolution of $\alpha$ as a function of density and ATH filler addition. No relationships between $\alpha$ and density are given in evidence for free ATH samples. $\alpha$ values ranged between $5.9 \times 10^{-7}$ and $8.6 \times 10^{-7} \mathrm{~m}^{2} \mathrm{~s}^{-1}$ for free ATH samples slightly close to values $\left(5.1 \times 10^{-7}-5.2 \times 10^{-7} \mathrm{~m}^{2} \mathrm{~s}^{-1}\right)$ obtained for hardwood from birch trees $\left(680 \mathrm{~kg} \mathrm{~m}^{-3}\right)^{52}$ and basalt aggregate concrete $\left(1520-1680 \mathrm{~kg} \mathrm{~m}^{-3}\right),{ }^{53}$ respectively. It should be noted that diffusivity values vary according to the used method in the literature. However, $\alpha$ increased significantly and reached values up to $11.1 \times 10^{-7}$ and $14.8 \times 10^{-7} \mathrm{~m}^{2} \mathrm{~s}^{-1}$ in the presence of the ATH fillers. The effect of ATH is high even with low ATH content (3.5 wt \%) and $\alpha$ values jump up to $30-40 \%$ for similar density and $\mathrm{BC}$ formulation. This behavior which is not in agreement with thermal conductivity results indicates that ATH could impact negatively the thermal insulation capacity of BCs by increasing the heat propagation velocity. Therefore, ATH fillers could act as a "bridge " to accelerate the conduction of heat flow $^{54}$ by increasing the thermal diffusivity of BCs.

Thermal effusivity is another important parameter which expresses the speed of heat absorption of a material. Figure 13 shows that thermal effusivity $(E)$ behaves like thermal conductivity $(\lambda)$ whatever the BC. $E$ increases with the increase of textile fibers contents and of density from $147 \pm 8$ (BC100/0-0) to

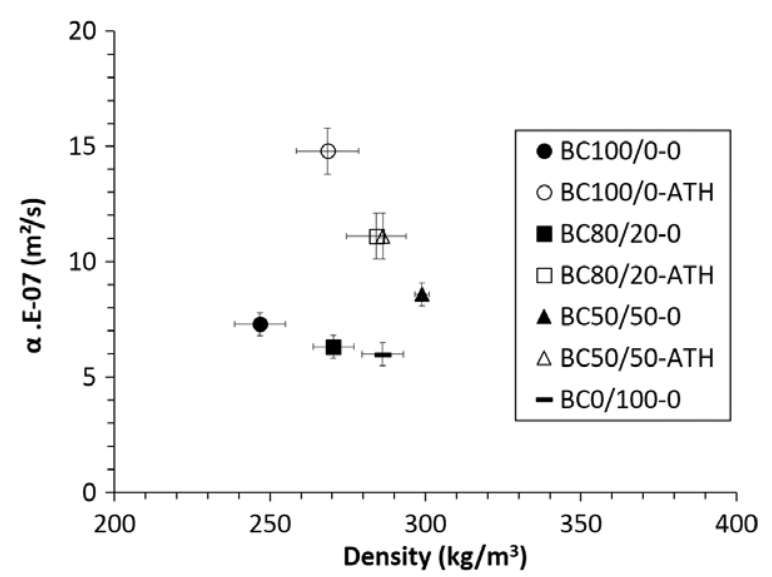

Figure 12. Evolution of thermal diffusivity $(\alpha)$ of the BCs as a function of density. 


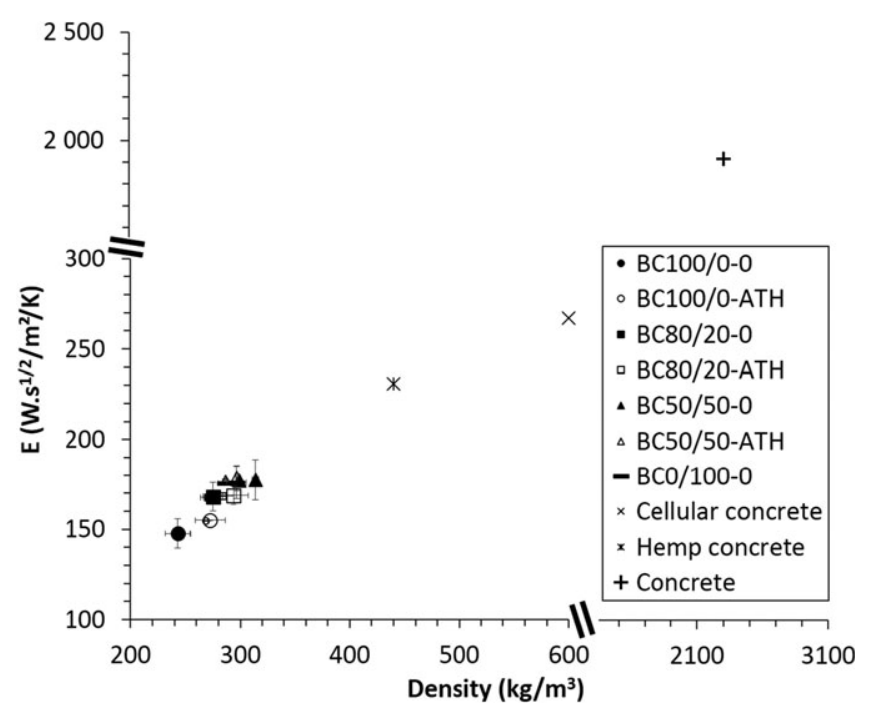

Figure 13. Evolution of thermal effusivity $(E)$ of the BCs as a function of density in comparison with the literature. ${ }^{55}$

$176 \pm 9(\mathrm{BC} 0 / 100-0) \mathrm{W} \mathrm{s}^{1 / 2} \mathrm{~m}^{-2} / \mathrm{K}^{-1}$ for free ATH samples and from $155 \pm 10$ (BC100/0-ATH) to $178 \pm 7$ (BC50/50-ATH) W $\mathrm{s}^{1 / 2} \mathrm{~m}^{-2} / \mathrm{K}^{-1}$ for ATH-based BCs. However, these values are lower than those obtained for hemp concrete, cellular concrete, and concrete $^{55}$ from literature and presented in Figure 13. This indicates that the BCs of this study possess low effusivity which could absorb energy while being heated notably and thus superheating problems in summer can occur if they are used as structural materials. Moreover, the presence of ATH filler did not shows any modification of this thermal parameter.

Mechanical Properties. Figure 14 (in vertical compressive mode) and Figure 15 (in horizontal compressive mode) show that BCs rigidity is higher in the vertical (elastic modulus in the range 5-16 MPa) than that of the horizontal (elastic modulus around $2 \mathrm{MPa}$ ) compression, that is, in the direction of the sample compression. This behavior is linked to the unidirectional compaction process where Mf will possess a particulate orientation in the perpendicular direction to horizontal compression. This orientation lead to lower modulus values in the horizontal compression caused by a folding and breakage of the fibers axis. However, in the vertical direction, a failure phenomena occurred in the direction of the fiber axis which leads to higher rigidity.

Compression mechanical properties of free ATH samples are first analyzed. Elastic compressive modulus of BC100/0-0 in the vertical state (Figure 14) is $10.0 \pm 1.6 \mathrm{MPa}$ which is $53 \%$ higher than those of $\mathrm{BC} 0 / 100-0(4.7 \pm 0.1 \mathrm{MPa})$. The highest modulus value was found for miscanthus/textile 80/20 and 50/50 BC which reached modulus values up to $15 \mathrm{MPa}$. Concerning the vertical compressive maximum stress $\left(\sigma_{\mathrm{cv}}\right)$, a low value was obtained for BC0/100-0 (0.24 $\pm 0.05 \mathrm{MPa})$ and $\mathrm{BC} 100 / 0-0 \quad(0.27 \pm 0.04$ $\mathrm{MPa})$. Highest values were obtained for miscanthus: RTf BCs BC80/20-0 (0.55 $\pm 0.03 \mathrm{MPa})$ and BC50/50-0 (0.69 \pm 0.01 $\mathrm{MPa})$. Moreover, the elongation at the vertical compressive maximum stress $\left(\varepsilon_{\mathrm{cv}}\right)$ increased proportionally to RTf content from $6.90 \pm 0.90 \%$ (BC0/100-0) to $10.3 \pm 0.31 \%$ (BC100/0-0).

Compression mechanical properties of ATH samples are secondly analyzed. It can be observed that elastic compressive modulus $E_{\mathrm{cv}}$ (increased in the presence of ATH for all the formulations $(+20 \%$ for $\mathrm{B} 100 / 0-\mathrm{ATH},+6 \%$ for $\mathrm{B} 80 / 20-\mathrm{ATH}$, and $+9 \%$ for B50/50-ATH). It can be assumed that ATH fillers are well dispersed and do not influence the material resistance for small strains. Moreover, vertical compressive maximum stress $\sigma_{\mathrm{cv}}$ and elongation at the maximum stress $\varepsilon_{\mathrm{cv}}$ increased in the presence of ATH fillers as a densification of ATH fillers could locally occur in the compression zone. Figure 15 shows the horizontal compressive mechanical properties. An equivalent behavior as those obtained for vertical compressive mode was given in evidence. As concerns the rigidity, the highest values of elastic modulus $\left(E_{\mathrm{f}}\right)$ were found for $\mathrm{BC} 80 / 20-0(2.7 \pm 0.5 \mathrm{MPa})$ and $\mathrm{BC} 50 / 50-0(2.9 \pm 0.5 \mathrm{MPa})$. The same trend was also found in the presence of ATH fillers. The highest values for stress at 5,10, and 20\% elongation were also found for the miscanthus/RTf BCs.

Elastic modulus $E_{\mathrm{f}}$, maximum stress $\sigma_{\mathrm{fM}}$, and elongation at the maximum stress $\varepsilon_{\mathrm{fM}}$ in the flexural mode for the different formulations are shown in Figure 16. $E_{\mathrm{f}}$ are 10 times higher than those obtained in the compression mode with the exception of BCs containing $100 \%$ of textile fibers which has similar values $(2.8 \pm 0.3 \mathrm{MPa})$. One can see that the rigidity of the samples increased significantly when mixing both miscanthus and RTf.

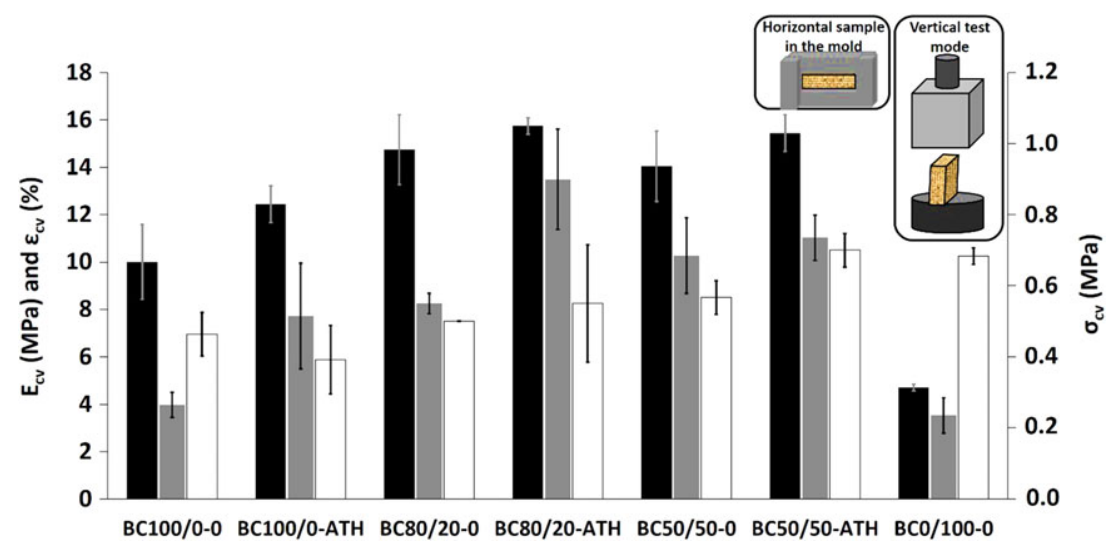

Figure 14. Vertical compressive mechanical properties (black bars: elastic modulus $E_{\mathrm{c} v}$; gray bars: elongation at maximum stress $\varepsilon_{\mathrm{cv}}$; white bars: maximum stress $\sigma_{\mathrm{cv}}$ ) for the BCs. [Color figure can be viewed at wileyonlinelibrary.com] 


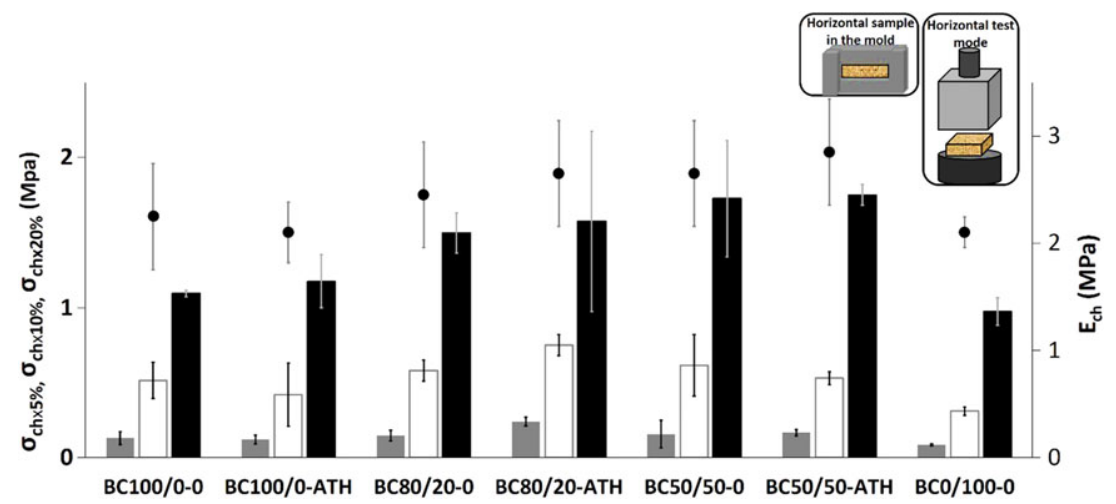

Figure 15. Horizontal compressive mechanical properties (black points: elastic modulus $E_{\mathrm{ch}}$; gray bars: stress at $5 \%$ elongation $\varepsilon_{\mathrm{chx} 5 \%}$; white bars: stress at $10 \%$ elongation $\varepsilon_{\mathrm{chx} 10 \%}$; black bars: stress at $20 \%$ elongation $\varepsilon_{\mathrm{chx} 20 \%}$ ) for all chitosan-based BCs. [Color figure can be viewed at wileyonlinelibrary.com]

For free ATH samples, $E_{\mathrm{f}}$ values for miscanthus-based composites (BC100/0-0) reached a value of $29 \pm 5 \mathrm{MPa}$. Higher rigidity is found for $\mathrm{BC} 80 / 20-0(37 \pm 9 \mathrm{MPa})$ followed by $\mathrm{BC} 50 / 50-0$ $(42 \pm 10 \mathrm{MPa})$ samples. Concerning $\sigma_{\mathrm{fM}}$ results, values remain close to those obtained by the compression mode. The highest values of $0.49 \pm 0.05 \mathrm{MPa}$ for $\sigma_{\mathrm{fM}}$ were also found for both mixed fibers samples (BC80/20-0 and BC50/50-0). Moreover, $\mathrm{BC} 0 / 100-0$ and $\mathrm{BC} 100 / 0-0$ feature the highest (6.2\%) and the lowest values (1.7\%) of $\varepsilon_{\mathrm{fM}}$, respectively. Replacing a fraction of Mf by the textile fibers results in a $50 \%$ decrease of $\varepsilon_{\mathrm{fM}}$ values. Same behavior is observed for ATH-based samples.

It can be notified that $\mathrm{BC} 80 / 20$ and $\mathrm{BC} 50 / 50$ with and without ATH shows higher mechanical properties than those exposed in literature by Binici et al. These authors obtained an average compressive and flexural strength of 0.3 and $0.07 \mathrm{MPa}$, respectively, for the sunflower stalks, cotton waste, and textile fiber insulating material using urea formaldehyde binder as a binder. ${ }^{16}$ However, mechanical properties obtained in this study remains lower than those obtained by Mati-Baouche et al. for the sunflower stalks particles/chitosan biobased composites in the compressive mode $\left(\sigma_{\mathrm{c}}=2.6 \mathrm{MPa} ; E_{\mathrm{c}}=25 \mathrm{MPa}\right){ }^{20}$ This is probably related to the higher amount of chitosan binder used in the design of their materials which reached values up to $15 \mathrm{wt} \%$ and corresponds to twice the value used in this study.
It can be concluded from these mechanical results obtained in compression and bending mode that mixing of miscanthus and textile fibers is very promising. Textile fibers seem to play a key role as mechanical coupling agent. Fibers mixing enhanced significantly the rigidity and the strength of the materials may due to good miscanthus/chitosan/textile interactions.

BCs Fire Behavior Using the Single Flame Source Fire Test. The fire test NF EN ISO 11925-2 was carried out on all chitosanbased BCs (Table VII). All BCs belong to Euroclass E rate because flame spread height $F_{\mathrm{s}}$ remains lesser than $150 \mathrm{~mm}$ after $60 \mathrm{~s}$ of flame application. BCs do not shrink away from the heat source when exposed to flame. Moreover, an absence of burning drops formation is noted which is characterized by an absence of ignition of the filter paper $\left(T_{\text {drip }}\right)$ for all the formulations. In comparing the free ATH formulations, it can be noticed that formulation containing only miscanthus is that which ignites. However, after $49 \mathrm{~s}$, sample extinguishing is observed. This formulation has the highest flame spread height $\left(F_{\mathrm{s}}\right.$ reached $120 \mathrm{~mm}$ ). The flame spread significantly decreases with the increase of textile fiber content in the composition of BCs. A char layer appeared immediately when the flame reaches the surface of the samples which acts as a barrier layer inhibiting the sample ignition. Additional analyzes were performed for the native miscanthus and textile fibers using PCFC to understand the

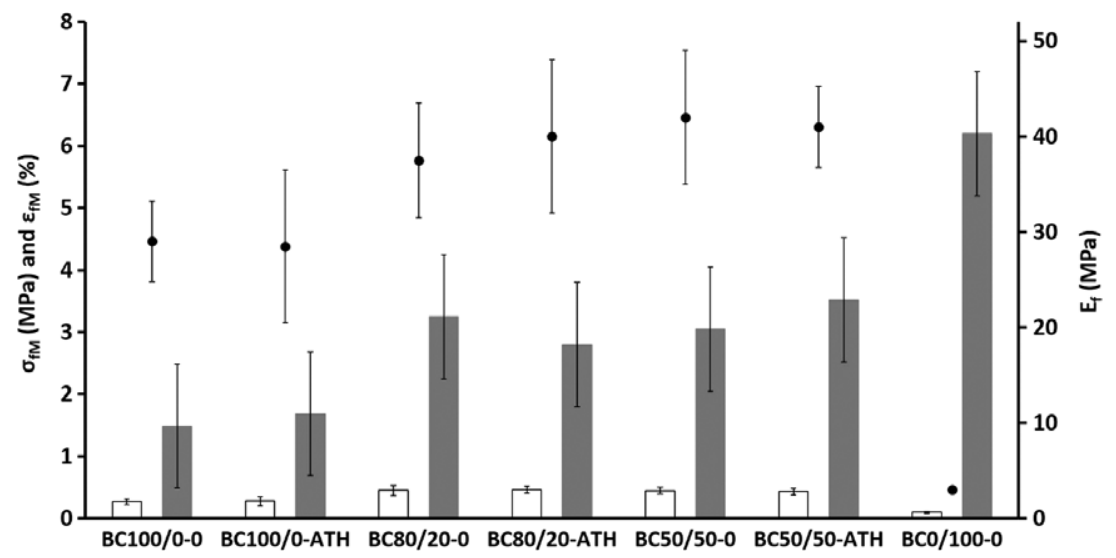

Figure 16. Flexural mechanical properties (black points: flexural modulus $E_{\mathrm{f}}$, gray bars: maximum elongation $\varepsilon_{\mathrm{fM}}$; white bars: maximum strength $\sigma_{\mathrm{fM}}$ ) for all chitosan-based BCs. 
Table VII. NF EN ISO 11925-2 Fire Test Results

\begin{tabular}{lllllll}
\hline Formulation & $F_{\mathrm{s}}{ }^{a}(\mathrm{~mm})$ & $T_{\text {igns }}{ }^{\mathrm{b}}(\mathrm{s})$ & $T_{\text {selfs }}{ }^{\mathrm{c}}(\mathrm{s})$ & $T_{\text {drip }}{ }^{\mathrm{d}}(\mathrm{s})$ & $T_{m}{ }^{\mathrm{e}}(\mathrm{s})$ & Euroclass \\
\hline BC100/0 & 120 & 3 & 26 & None & None & $\geqslant E$ \\
BC100/0-ATH & 70 & 11 & 18 & None & None & $\geqslant E$ \\
BC80/20 & 40 & None & None & None & None & $\geqslant E$ \\
BC80/20-ATH & 25 & None & None & None & None & $\geqslant E$ \\
BC50/50-0 & 60 & None & None & None & None & $\geqslant E$ \\
BC50/50-ATH & 35 & None & None & None & None & $\geqslant E$ \\
BC0/100-0 & 50 & None & None & None & None & $\geqslant E$ \\
\hline
\end{tabular}

a $F_{\mathrm{s}}(\mathrm{mm})=$ Flame spread height.

b $T_{\text {igns }}(\mathrm{s})=$ Ignition time.

c $T_{\text {selfs }}=$ Self-extinguishing time

d $T_{\text {drip }}=$ Ignition time of the paper filter.

e $T_{m}(\mathrm{~s})=$ Time when flame tip reaches $150 \mathrm{~mm}$.

improvement of the fire behavior observed after integrating the textile fibers reinforcement. It appears from these analyses that textile fibers possess much lower $\mathrm{pHRR}$ and THR values than that of miscanthus $\left(\mathrm{pHRR}=56 \pm 1 \mathrm{~W} \mathrm{~g}^{-1}\right.$ against $101 \pm 2 \mathrm{~W} \mathrm{~g}^{-1}$ and $\mathrm{THR}=3.6 \pm 0.2 \mathrm{KJ} \mathrm{g}^{-1}$ against $8.5 \pm 0.3 \mathrm{KJ} \mathrm{g}^{-1}$, respectively). These lower values of pHRR and THR indicate that the use of these recyclable fibers is advantageous in the design of a better fire resistant material for applications in the building sector.

By comparing each formulation with and without ATH, it is obviously clear that the addition of this mineral filler decreases significantly $F_{\mathrm{s}}$ which was reduced by $40 \%$. Moreover, it is quite remarkable that ATH addition delayed the ignition time $\left(T_{\text {igns }}\right)$ from 3 to $11 \mathrm{~s}$ and slightly improves the flame self-extinguishing ( $T_{\text {selfs }}$ ) from 26 to $18 \mathrm{~s}$ for the $100 \%$ miscanthus BCs.

This ATH chitosan-based FR system seems to be more effective from the chitosan/sodium polyphosphate system developed for cotton fabric. ${ }^{23}$ Authors mentioned that the use of this system exhibited only a moderate degree of flame retardancy performance. More over, Fang et al. ${ }^{30}$ have developed another intumescent FR coating, composed of cationic chitosan and anion ammonium polyphosphate on cotton fabric by layer-by-layer assembly technique. An excellent FR efficiency on cotton fabric was observed. However, flame propagation was observed on the cotton fabric despite the highest residues formation and fiber shape remaining.

The results obtained from the present work indicates clearly an effective synergy of the chitosan/ATH system despite the low content of ATH content in the BCs design, which results in an effective improvement of the fire behavior. These observations are in agreement with the TGA and PCFC results obtained on the chitosan and chitosan/ATH films.

\section{CONCLUSIONS}

Chitosan and chitosan/ATH films with various compositions have been successfully prepared via the solvent evaporation technique. Physical, thermal, and mechanical properties of the different prepared film showed a significant effect of the gradual addition of the ATH filler on the various properties. ESEM suggests a good dispersion with the absence of aggregate formation as the content of ATH is $\leq 33$ wt $\%$. TGA analysis showed a significant slowdown in the degradation of the chitosan main chain for a minimum ATH content of $33 \mathrm{wt} \%$ without any improving in the charring behavior. PCFC analysis showed low values of heat release for pure chitosan which was significantly decreased up to $50 \%$ in the presence of 33 wt \% of ATH content. DSC results showed any effect of the ATH addition on the films behavior aside the reduction of the physisorbed water peak. The result on mechanical properties showed that the tensile properties of the reinforced chitosan films were inferior to the free ATH film. Modulus and maximum tensile strength decreased up to $50 \%$ after a minimum addition of $33 \mathrm{wt}$ $\%$ of ATH.

However, the main goal of this work was to develop new ignifuged BCs materials based on miscanthus and RTf using ATH. Thermal, mechanical, and fire behavior of the developed BCs were investigated. It emerges from this study that thermal conductivity values are slightly increased for BCs designed by mixing miscanthus and RTf and after ATH addition. However, their different BCs are considered as insulating materials despite their high density $\left(\geq 250 \mathrm{~kg} \mathrm{~m}^{-3}\right)$. It was clearly shown that mechanical properties were improved by combining miscanthus and textile fibers. Moreover, the presence of ATH in the materials design increased the rigidity of the samples contrary to the results observed for the films. The different BCs show an interesting fire behavior using chitosan as a matrix. Moreover, results showed that ATH integration (only $3.5 \mathrm{wt} \%$ in the total BC design) significantly improved this behavior. This work has successfully allowed the obtention of E Euroclass fire rating BCs in standardized fire test NF EN ISO 11925-2. The flame retardancy modeof-action of BCs by chitosan/ATH system is attributed to the barrier effect allowed by ATH filler which together induced flame inhibition. These results highlighted the potential use of chitosan/ATH (67/33 wt \%) system for the design of nonflammable insulating materials.

\section{ACKNOWLEDGMENTS}

This work was supported by the Université Libanaise "Development and Innovation Project 2016-2018 (PANATEXT)”. The authors gratefully acknowledge EARL GozennAr and Le Relais 
companies for supplying freely the reinforcement used in this work. The authors would also like to thank IMT Mines Ales technical staffs Moussa Semega and Marc Longerey for their help in carrying out the mechanical analysis; and Loic Dumazert who contributed in the production of the fire test NF EN ISO 11925-2. Roland EL HAGE also addressed his thanks to "Agence Universitaire de la Francophonie" for its support by funding a research allocation grants in September 2016 to achieve some experimental analyses in France.

\section{REFERENCES}

1. Hamdani-Devarennes, S.; El Hage, R.; Dumazert, L.; Sonnier, R.; Ferry, L.; Lopez-Cuesta, J. -M.; Bert, C. Prog. Org. Coat. 2016, 99, 32.

2. Clifton-Brown, J. C.; Lewandowski, I. Ann. Bot. 2000, 86(1), 191.

3. Lewandowskia, I.; Scurlock, J. M. O.; Lindvall, E.; Christoud, M. Biomass Bioenergy. 2003, 25, 335.

4. Alexopoulou, E., Christou, M., Eleftheriadis, I. Role of $4 \mathrm{~F}$ cropping in determining future biomass potentials, including sustainability and policy related issues. Biomass Department of CRES Report. http://www.biomassfutures.eu/work_packages/ WP3\%20Supply/D3.2\%20Role\%20of\%204F\%20cropping\% 20in\%20determining\%20future\%20biomass.pdf (October 2010).

5. Venendaal, R.; Jqrgensen, U.; Fosters, C. A. Biomass Bioenergy. 1997, 13(3), 147.

6. Ragoubi, M.; George, B.; Molina, S.; Bienaimé, D.; Merlin, A.; Hiver, J. -M.; Dahoun, A. Compos. Part A. 2012, 43(4), 675.

7. Johnson, M.; Tucker, N.; Barnes, S.; Kirwan, K. Ind. Crops Prod. 2005, 22(3), 175.

8. Bourmaud, A.; Pimbert, S. Compos. Part A. 2008, 39(9), 1444.

9. Briga-Sá, A.; Nascimento, D.; Teixeira, N.; Pinto, J.; Caldeira, F.; Varum, H.; Paiva, A. Construct. Build Mater. 2013, 38, 155.

10. Le Relais, Métisse ${ }^{\circledR}$, Available at: http://www.isolantmetisse. com/rubriques/documents-techniques.

11. Algin, H. M.; Turgut, P. Construct. Build Mater. 2008, 22, 1074.

12. Binici, H.; Aksogan, O.; Shah, T. Construct. Build Mater. 2005, 19, 313.

13. Bindiganavile, V.; Islam, M. T.; Chan, R. Appl. Mech. Mater. 2011, 82, 565.

14. Barbero-Barrera, M.; Pombo, O.; Navacerrad, M. Compos. Part B. 2016, 94, 26.

15. Dos Reis, J. M. L. Mater. Res. 2009, 12, 63.

16. Binici, H.; Eken, M.; Dolaz, M.; Aksogan, O.; Kara, M. Construct. Build Mater. 2014, 51, 24.

17. El Mansouri, N. E.; Pizzi, A.; Salvado, J. Holz Roh Werkst. 2007, 65, 65.

18. Ping, L.; El Hage, R.; Pizzi, A.; Ding Guo, Z.; Brosse, N. J. Biobased Mater.Bioenergy. 2011, 5, 1.
19. El Hage, R.; Brosse, N.; Navarrete, P.; Pizzi, A. Adhes. Sci. Technol. 2010, 25, 1549.

20. Mati-Baouche, N.; De Baynast, H.; Lebert, A.; Sun, S.; Lopez-Mingo, C. J. S.; Leclaire, P.; Michaud, P. Ind. Crops Prod. 2014, 58, 244.

21. Fu, S.; Song, P.; Liu, X. In Advanced High Strength Natural Fiber Composites in Construction; Mizi, F.; Feng, F., Eds., Zhejiang A \& F University: Linan, Hangzhou, China, 2017, Chapter 19.

22. Dorez, G.; Taguet, A.; Ferry, L.; Lopez-Cuesta, J. M. Polym. Degrad. Stab. 2013, 98, 87.

23. Levchik, S. V.; Weil, E. D. Fire Sci. 2006, 24, 345.

24. Lu, S.-Y.; Hamerton, I. Prog. Polym. Sci. 2002, 27, 1661.

25. Hull, T. R.; Witkowski, A.; Hollingbery, L. Polym. Degrad. Stab. 2011, 96(8), 1462.

26. Liu, L.; Qian, M.; Song, P.; Huang, G.; Yu, Y.; Fu, S. ACS Sustain. Chem. Eng. 2016, 4(4), 2422.

27. Chapple, S.; Anandjiwala, R. J. Thermoplast. Compos. Mater. 2010, 23(6), 871.

28. Charuchinda, S.; Srikulkit, K.; Mowattana, T. J. Sci. Res. Chula. Univ. 2005, 30(1), 97.

29. Pan, Y.; Zhan, J.; Pan, H.; Wang, W.; Tang, G.; Song, L.; Hu, Y. ACS Sustain. Chem. Eng. 2016, 4(3), 1431.

30. Fang, F.; Zhang, X.; Meng, Y.; Gu, Z.; Bao, C.; Ding, X.; Li, S.; Chen, X.; Tian, X. Surf. Coat. Technol. 2015, 262, 9.

31. Xiao, Y.; Zheng, Y.; Wang, X.; Chen, Z.; Xu, Z. Appl. Polym. 2014, 131, 40.

32. Shittu, T. A.; Jayaramudu, J.; Sivakumar, D.; Sadiku, E. R. Food Bioproc. Tech. 2014, 7, 24.

33. Zhao, J.; Han, W.; Chen, H.; Tu, M.; Zeng, R.; Shi, Y.; Cha, Z.; Zhou, C. Carbohydr. Polym. 2011, 83(4), 1541.

34. López, F.; Mercê, A.; Alguacil, F.; López-Delgado, A. J. Therm. Anal. Calorim. 2007, 91(2), 633.

35. Guinesi, L. S.; Cavalheiro, E. T. G. Thermochim. Acta. 2006, 444(2), 128.

36. Martínez-Camacho, A. P.; Cortez-Rocha, M. O.; EzquerraBrauer, J. M.; Graciano-Verdugo, A. Z.; Rodriguez-Félix, F.; Castillo-Ortega, M. M.; Yépiz-Gómez, M. S. Carbohydr. Polym. 2010, 82(2), 305.

37. Friederich, B. Développement de Nouveaux Systèmes Retardateurs de Flammes à Base de Nanocomposites Plus Respectueux de l'environnement. Ph.D. Thesis, University of Paul Verliane Metz, August 2011.

38. El Hage, R.; Viretto, A.; Sonnier, R.; Ferry, L.; LopezCuesta, J. -M. Polym. Degrad. Stab. 2014, 108, 56.

39. Wu, K.; Shen, M.-M.; Hu, Y.; Xing, W.; Wang, X. J. Therm. Anal. Calorim. 2011, 104, 1083.

40. Jesús Fernández, M.; Dolores Fernández, M.; Aranburu, I. Eur. Polym. 2013, 49, 1257.

41. Wolska, A.; dzikiewicz, M. G.; Ryszkowska, J. J. Mater. Sci. 2012, 47, 5627.

42. Rueda, D. R.; Secall, T.; Bayer, R. K. Carbohydr. Polym. 1999, 40, 49. 
43. Sun, G.; Zhang, X. -Z.; Chu, C. -C. Mater. Sci. Mater. Med. 2007, 18(8), 1563.

44. Neto, C. G. T.; Giacometti, J. A.; Job, A. E.; Ferreira, F. C.; Fonseca, J. L. C.; Pereira, M. R. Carbohydr. Polym. 2005, 62, 97.

45. Srinivasa, P. C.; Ravi, R.; Tharanathan, R. N. Food Eng. 2007, 80, 184.

46. Mati-Baouche, N.; De Baynast, H.; Vial, C.; Audonnet, F.; Sun, S.; Petit, E.; Pennec, F.; Prevot, V.; Michaud, P. Appl. Polym. Sci. 2015, 132(2), 1.

47. Abdou, A.; Boudaiwi, I. Construct. Build Mater. 2013, 43, 533.

48. Yenier, Z.; Seki, Y.; Sen, I.; Sever, K.; Mermer, O.; Sarikanat, M. Compos. Part B. 2016, 98, 281.
49. Evon, P.; Vandenbossche, V.; Pontalier, P. -Y.; Rigal, L. Ind. Crops Prod. 2014, 52, 354.

50. Chikhi, M.; Agoudjil, B.; Boudenne, A.; Gherabli, A. Energ. Buildings. 2013, 66, 267.

51. Taoukil, D.; El bouardi, A.; Sick, F.; Mimet, A.; Ezbakhe, H.; Ajzoul, T. Construct. Build Mater. 2013, 48, 104.

52. Suleiman, B. M.; Larfeldt, J.; Leckner, B.; Gustavsson, M. Wood Sci. Technol. 1999, 33, 465.

53. Marshall, A. L. Build. Sci. 1972, 7, 167.

54. Bigg, D. M. Polym. Eng Sci. 1979, 19(16), 1188.

55. Maalouf, C.; Tran Le, A. D.; Umurigirwa, S. B.; Lachi, M.; Douzane, O. Energ. Buildings. 2014, 77, 48. 